\title{
THE EFFECT OF ATTACHMENT STYLE AND RELIGIOUSITY TOWARD DATING VIOLENCE AMONG ADOLESCENT
}

\author{
Farah Hanifa Purnomo \\ Farahhanifa13@gmail.com \\ mailto:afifah.fauziyyah.af@gmail.com \\ Guru BK di Bintang Pelajar
}

\author{
Bambang Suryadi \\ bang1970@gmail.com
}

Fakultas Psikologi UIN Syarif Hidayatullah Jakarta

\begin{abstract}
On adolescence, there are some changes that occur. One of them is emotionally changes that causing the interest feeling with opposite sex emerge. In this era, dating on adolescent is not a new thing. However, the impacts of dating become more serious. One of them is dating violence amongst adolescent couples. The objective of this study is to examine the effect of attachment style, religiousity and gender toward dating violence among adolescent. Samples are 209 students which were taken with convenience technique. The three scales that used in this study are dating violence scale, religiousity scale, and attachment style scale. Their validities are examined by confirmatory factor analysis (CFA). Meanwhile, the method that used is multiple regression. Findings were consistent with previous research. The findings show that religiousity, attachment style and gender has significant effect toward dating violence among adolescent. All of the independent variabels have implication about 10,5\%, and the others were affected by variables outside the research. After the proportion variance were analyzed, the results show that fearful avoidant, which is dimension of attachment style, and gender are the biggest predictors toward dating violence. For better result, we suggest to use bigger sample size.
\end{abstract}

Keyword : dating violence, attachment style, religiousity

\begin{abstract}
Abstrak
Ketika memasuki masa remaja, terdapat berbagai perubahan yang terjadi. Salah satunya adalah perubahan emosional yang menyebabkan munculnya ketertarikan dengan lawan jenis. Hal ini menyebabkan, fenomena pacaran menjadi semakin marak di kalangan remaja. Padahal terdapat beberapa dampak dari pacaran, salah satunya adalah terjadinya dating violence. Oleh karena itu, penelitian ini bertujuan untuk mengetahui pengaruh variabel attachment style, religiusitas dan jenis kelamin terhadap dating violence pada remaja. Sampel adalah siswa SMAN 87 Jakarta Selatan dan SMK Tunas Pembangunan berjumlah 209 siswa, yang diambil dengan teknik convenience. Instrumen yang digunakan dalam penelitian ini terdapat tiga skala, yaitu skala dating violence, skala religiusitas, dan skala attachment style. Uji validitas alat ukur menggunakan teknik confirmatory factor analysis (CFA). Sedangkan analisis data menggunakan teknik multiple regression. Hasil penelitian ini menunjukkan bahwa ada pengaruh yang signifikan dari variabel attachment style, religiusitas dan jenis kelamin terhadap dating violence pada remaja. Besarnya pengaruh seluruh variabel independen terhadap dating violence adalah sebesar 10,5\%, sedangkan 89,5\% sisanya dipengaruhi oleh variabel lain di luar penelitian ini. Sementara hasil analisis proporsi varians masing-masing variabel secara terpisah, ditemukan sumbangan yang paling besar terhadap dating violence adalah fearful-avoidant, dari variabel attachment style, dan jenis kelamin. Penelitian ini akan mendapatkan hasil yang lebih baik apabila menggunakan jumlah sampel yang lebih banyak dan lebih beragam.
\end{abstract}

Kata kunci: $\quad$ kekerasan dalam pacaran, attachment style, religiusitas 


\section{PENDAHULUAN}

Periode remaja merupakan periode peralihan dari masa kanak-kanak, sehingga terdapat beberapa tugas perkembangan baru yang harus dipenuhi. Salah satu tugas remaja yaitu mulai menjalin hubungan pertemanan yang lebih erat dengan teman sebaya. Remaja dituntut untuk menjalin hubungan pertemanan yang sehat dan lebih luas dengan teman sebaya, laki-laki maupun perempuan (Santrock, 2008). Namun, secara emosional remaja juga akan mulai mengalami ketertarikan dengan lawan jenis. Rasa senang yang muncul terhadap lawan jenis disertai dengan perasaan ingin memiliki, menjadikan pacaran sebagai cara yang dianggap efektif untuk menyalurkan perasaan. Sehingga pada kalangan remaja, fenomena pacaran di zaman sekarang tidak lagi menjadi hal yang aneh ataupun asing. Perilaku yang seharusnya dilakukan oleh orang dewasa pada usia siap menikah dengan tujuan untuk lebih mengenal dan mengidentifikasi calon pendamping hidup kini mulai diikuti oleh remaja, bahkan anak usia sekolah (Tempo.co, 2012). Bagi sebagian remaja, memiliki pacar merupakan sesuatu yang sangat dibanggakan dan menjadi cara untuk dapat diakui oleh kelompok, serta meningkatkan status sosial seseorang. Sehingga, memiliki pacar di kalangan remaja tidak saja menjadi kebutuhan biologis tetapi juga menjadi kebutuhan sosiologis (Barokah, 2016).

Bentuk pacaran yang dilakukan remaja pada umumnya adalah dengan melakukan aktivitas seperti jalan bersama, berduaan di tempat yang sepi, berpegangan tangan hingga melakukan hubungan seksual di luar nikah. Jika ditinjau berdasarkan definisi, pacaran atau dating adalah hubungan antara dua individu yang saling berbagi emosi, kemesraan, serta hubungan seksual yang melebihi hubungan pertemanan, namun bukan dalam hubungan pernikahan atau bertunangan (Murray \& Kardatzke, 2007). Dari definisi tersebut, perilaku yang ditekankan dari dating adalah melakukan hubungan seksual bersama. Oleh sebab itu, salah satu dampak dari pacaran (dating) adalah semakin banyak remaja yang melakukan hubungan seksual dengan pacar. Survei yang dilakukan oleh Badan Penelitian dan Pengembangan (Bandiklat) Kaltim Post pada tahun 2015 menunjukkan bahwa setidaknya sebanyak $16 \%$ dari remaja mengaku pertama kali berpegangan tangan dengan pacar pada usia sembilan tahun (kaltim.prokal.co, 2015).

Dalam pandangan Islam, aktivitas berduaan hingga melakukan hubungan seksual di luar nikah disebut dengan zina. Agama Islam telah melarang segala bentuk zina, bahkan tindakan yang mengarah kepada zina pun dilarang. Islam sebagai agama yang memiliki adab dan syariat, mengetahui dampak negatif yang ditimbulkan dari pacaran, karena akan merugikan baik itu dari segi sosial maupun moral. Selain memicu bertambahnya jumlah remaja melakukan hubungan seksual, dampak lain dari fenomena pacaran pada remaja adalah terjadinya tindakan-tindakan kekerasan yang dilakukan oleh pacar atau disebut dengan dating violence. Di barat, kasus dating violence telah menjadi salah satu masalah penting dikalangan remaja, karena mayoritas remaja tidak menyadari mengenai bentuk-bentuk dating violence yang terjadi dalam hubungan mereka. Symons, Groër, Kepler-Youngblood, dan Slater (1994) dalam penelitiannya mengungkapkan sebanyak $60 \%$ dari remaja di Amerika mengaku 
paling tidak mengalami sebanyak satu kejadian kekerasan dalam hubungan pacaran mereka. Namun menariknya, hanya $12,7 \%$ dari remaja yang menganggap hal tersebut sebagai kekerasan (abuse). Temuan yang menarik dari penelitian ini menunjukkan bahwa hanya sedikit dari remaja yang mengetahui bahwa pacar mereka telah menjadi pelaku kekerasan.

Tidak berbeda dengan di barat, di Indonesia sendiri kasus dating violence cukup mengkhawatirkan. Salah satu himbauan pernah disampaikan oleh Meutia Hatta mengenai kasus dating violence pada remaja di Indonesia. Beliau menyatakan bahwa "harus diwaspadai adanya kekerasan di masa pacaran atau dating violence. Karena satu dari lima remaja putri di Indonesia pernah mengalami kekerasan dalam masa pacaran". Hal tersebut menunjukkan bahwa kasus dating violence di Indonesia cukup banyak terjadi, namun fakta ini seolah-olah tidak terlihat (Detiknews.com, 2008).

Selain itu, berdasarkan survei yang dilakukan oleh Komisi Nasional AntiKekerasan Terhadap Perempuan (Komnas Perempuan) pada tahun 2014, dari sekitar 800 laporan kasus yang berkaitan dengan kekerasan terhadap perempuan, sebanyak 59\% kekerasan terjadi pada wilayah perkawinan (domestic violence), $21 \%$ adalah kasus kekerasan dalam pacaran (dating violence), dan 20\% lainnya adalah kekerasan pada anak-anak. Dengan adanya hasil survei tersebut, maka kekerasan yang dilakukan oleh pasangan selama masa pacaran bukanlah suatu hal yang remeh dan tidak menutup kemungkinan untuk berlanjutnya tindakan kekerasan pada wilayah pernikahan (Magdalene.co, 2015).

Adanya fakta bahwa kasus dating violence menjadi semakin marak, tidak hanya di barat tetapi juga di Indonesia, maka muncul pertanyaan apakah yang menyebabkan seseorang dapat melakukan dating violence? Terdapat beberapa faktor yang mempengaruhi seseorang melakukan dating violence, baik faktor internal maupun eksternal. Faktor internal salah satunya adalah attachment style, yaitu sebuah ikatan emosional yang kuat antara seseorang dengan figur tertentu dalam sebuah hubungan dekat, bisa berarti orang tua, teman, sahabat, maupun pacar (Bartholomew, 1990). Namun dalam penelitian ini sebagai attachment pada teman sebaya.

Penelitian Henderson, Bartholomew, dan Dutton (1997) (dalam McVay, 2009), menguji korelasi attachment style, yaitu fearful-avoidant attachment style, preoccupied attachment style, dismissing attachment style dan secure attachment style dengan dating violence. Penelitian tersebut menemukan bahwa semakin negatif selfmodel seseorang, maka semakin besar kemungkinan mereka melakukan dating violence. Orang dengan tipe fearfull-avoindant, dengan karakteristik yang mudah cemas dan posesif, memang akan memiliki hubungan pacaran yang lebih awet, tetapi mereka cenderung akan lebih sering melakukan dating violence, terutama kekerasan fisik dan emosi. Sebaliknya, orang dengan tipe secure dan dismissing attachment style akan lebih kecil kemungkinan menjadi pelaku maupun korban dating violence. Selain itu, Bookwala dan Zdaniuk (1998) (dalam McVay, 2009) juga menemukan bahwa tipe preoccupied dan fearful-avoidant berkaitan erat dengan terjadinya dating violence. Kedua tipe tersebut akan lebih sering melakukan tindakan agresi dibandingkan dengan tipe secure dan dismissing. 
Sementara itu, penelitian Miga, et.al. (2010) juga mendukung adanya hubungan antara attachment style dengan tindakan agresi dalam masa pacaran. Hasil menunjukkan bahwa orang dengan tipe preoccupied lebih sering melakukan kekerasan verbal pada pasangan mereka. Mereka akan lebih mudah marah ketika terjadi konflik, sehingga mereka akan lebih tinggi melakukan kekerasan secara verbal, seperti mengeluarkan perkataan yang tidak menyenangkan pada pasangan. Namun sebaliknya, orang dengan tipe dismissing diprediksi akan menjadi korban kekerasan verbal oleh pasangan mereka. Seseorang dengan tipe dismissing cenderung akan menghindari melakukan kekerasan fisik dan verbal, juga mereka menghindari melakukan diskusi secara langsung ketika konflik terjadi. Dengan demikian, seseorang dengan tipe secure dan dismissing memiliki pengaruh negatif terhadap dating violence, artinya individu dengan secure dan dismissing lebih sering menjadi korban dating violence. Sementara preoccupied dan fearful-avoidant attachment style memiliki pengaruh positif terhadap dating violence, artinya individu dengan preoccupied dan fearful-avoidant lebih sering menjadi pelaku dating violence.

Sementara yang merupakan salah satu faktor eksternal adalah religiusitas. Religiusitas adalah pikiran dan keyakinan yang dimiliki seseorang untuk memandang dunia sehingga mempengaruhi pengalaman dan perilaku mereka dalam kehidupan sehari-hari (Huber \& Huber dalam Murken \& Namini, 2004). Religiusitas merupakan faktor eksternal yang berbeda dalam setiap individu. Perbedaan tingkat religiusitas ini dapat mempengaruhi seseorang melakukan kekerasan pada pasangan mereka. Religiusitas dapat diukur dari beberapa hal, salah satunya adalah seberapa intens seseorang beribadah di tempat ibadah. Stark dan Glock (1974) menyebut intensitas seseorang beribadah di tempat ibadah dengan religios practice, sementara Huber dan Huber (2012) menyebutnya dengan public practice.

Penelitian Mynat dan Allgeier (1990) menguji tingkat religiusitas seseorang, yang diukur melalui intensitas seseorang menghadiri tempat ibadah, dengan terjadinya sexual coercion. Hasil menunjukkan bahwa seseorang yang jarang menghadiri tempat ibadah dilaporkan lebih banyak menjadi korban sexual coercion dibandingkan dengan mereka yang sering menghadiri tempat ibadah.

Sejalan dengan penelitian Ellison dan Anderson (2001) menunjukkan bahwa tingkat religiusitas seseorang memiliki hubungan negatif dengan dating violence. Laki-laki yang lebih sering hadir dalam ibadah keagamaan ditempat ibadah memiliki kecenderungan lebih kecil untuk melakukan kekerasan pada pasangan daripada yang tidak pernah hadir dalam ibadah keagamaan. Hal ini disebabkan, ketika seseorang yang lebih sering hadir dalam ibadah keagamaan akan lebih sering mendapatkan nasehat atau ceramah mengenai ajaran agama dari pemuka agamanya. Karena pada dasarnya dalam setiap ajaran agama tidak menganjurkan untuk melakukan kekerasan.

Sehingga, religiusitas memiliki pengaruh negatif dengan dating violence. Artinya individu yang memiliki religiusitas yang tinggi memiliki kecenderungan yang kecil untuk melakukan dating violence. Sedangkan pengaruh jenis kelamin terhadap dating violence telah banyak dijelaskan dalam penelitian sebelumnya. Penelitian Caldwell, Swan dan Woodbrown (2012) menemukan adanya 
pengaruh yang besar dari peran gender terhadap kekerasan pada pasangan. Gender menjadi besar pengaruhnya karena adanya korelasi yang sangat tinggi dengan power. Adanya anggapan bahwa laki-laki lebih berkuasa dan kuat dibandingkan perempuan menyebabkan kekerasan yang dilakukan oleh laki-laki lebih banyak terjadi. Selain itu, penelitian Anderson (2007) juga mendukung hasil tesebut. Anderson (2007) menambahkan bahwa perempuan yang bergantung secara ekonomi pada pasangannya akan lebih sulit untuk menghindari kekerasan dalam hubungannya. Meskipun dalam kasus dating violence, perempuan juga dapat menjadi pelaku dating violence. Dalam penelitian Williams, at.al. (2008) menjelaskan bahwa perempuan juga dapat melakukan kekerasan terhadap lakilaki. kekerasan yang dilakukan dapat berupa kekerasan fisik dan kekerasan seksual, namun kekerasan yang banyak dilakukan perempuan adalah kekerasan secara psikologis.

Berdasarkan pemaparan di atas, penulis ingin menguji bagaimana pengaruh attachment style dan religiusitas terhadap dating violence, dimensi mana saja dari masing-masing variabel yang memberikan pengaruh dan berapa besar pengaruhnya.

\section{KAJIAN TEORI}

\section{Dating Violence}

Dari definisi yang telah dipaparkan, meskipun terdapat perbedaan dari setiap tokoh. Namun terdapat kata kunci yang sama dalam setiap definisi yaitu perilaku mengontrol pasangan yang pada umumnya dilakukan secara fisik. Definisi dating violence yang dimaksud dalam penelitian ini adalah perilaku mengontrol, mendominasi dan merugikan orang lain baik secara fisik, seksual, maupun psikologis. Definisi yang digunakan berdasarkan pendapat Wekerle dan Wolfe (1999) karena definisi tersebut lebih spesifik untuk menjelaskan dating violence pada remaja dimana bentuk kekerasan yang paling banyak terjadi adalah dalam bentuk kekerasan fisik, seksual dan psikologis.

\section{Attachment Style}

Dari pemaparan definisi di atas, terdapat persamaan dalam mendefinisikan attachment style, yaitu ikatan emosional dengan orang lain. Definisi attachment style dalam penelitian ini adalah sebuah ikatan emosional yang kuat antara seseorang dengan figur tertentu dalam sebuah hubungan dekat, bisa berarti orang tua, teman, sahabat, maupun pacar, namun dalam penelitian ini berarti teman sebaya. Definisi ini sesuai dengan pendapat Bartholomew (1990), karena dianggap lebih sesuai dengan maksud penelitian ini dan mengukur dengan lebih spesifik.

\section{Religiusitas}

Dalam penelitian ini, religiusitas didefinisikan sebagai pikiran dan keyakinan yang dimiliki seseorang untuk memandang dunia sehingga mempengaruhi pengalaman dan perilaku mereka dalam kehidupan sehari-hari. Definisi yang digunakan sesuai dengan pendapat Huber (Murken \& Naminidalam Pye, Frank, Wasim \& Ma'sud, 2004) dengan alasan karena definisi tersebut lebih cocok untuk mengukur religiusitas remaja dimana religiusitas diukur dari rutinitas remaja melakukan ibadah dan keyakinan remaja pada agama. 


\section{METODE PENELITIAN}

\section{Populasi, sampel dan teknik pengambilan sampel}

Populasi dalam penelitian ini adalah siswa kelas X, XI dan XII SMAN 87 Jakarta Selatan dan SMK Tunas Pembangunan Jakarta Selatan, yang berjumlah 1.160 siswa. Karakteristik populasi adalah siswa yang sedang menjalani atau paling tidak selama satu tahun terakhir pernah pacaran. Teknik pengambilan sampel yang akan digunakan dalam penelitian ini adalah nonprobability sampling dengan metode convenience. Peneliti mendatangi kedua sekolah tersebut, kemudian siswa mana saja yang sedang menjalani atau paling tidak selama satu tahun terakhir pernah pacaran akan menjadi sampel dalam penelitian ini. Dari hasil penyebaran kuesioner di dua sekolah, peneliti mendapatkan sampel sebanyak 307 orang, namun hanya 209 orang yang dianalisis lebih lanjut karena memenuhi kriteria penelitian dan menjawab kuesioner dengan lengkap.

\section{Instrumen Penelitian}

Terdapat tiga alat ukur yang digunakan dalam penelitian ini, yaitu:

\section{Skala dating violence}

Skala dating violence memodifikasi dari alat ukur CADRI yang disusun oleh Wolfe et.al. (2001). CADRI terdiri dari 25 item, kemudian peneliti menambahkan 14 item, sehingga skala dating violence terdiri dari $39 \mathrm{item}$. Alasannya adalah peneliti membagi atau membedakan menjadi lebih spesifik bentuk-bentuk kekerasan yang dilakukan. Item dalam skala ini terdiri favorable dan unfavorable. Dating violence diukur melalui lima dimensi, yaitu physical abuse terdiri dari 8 item, sexual abuse terdiri dari 4 item, threatening behavior terdiri dari 6 item, relational abuse terdiri dari 6 item dan verbal emotional abuse terdiri dari 15 item.

\section{Skala attachment style}

Attachment style diukur dengan memodifikasi skala Adolescent- Relationships Questionnaire (ARQ) oleh Scarfe \& Bartholomew (1995). Item dalam skala ini berbentuk favorable. Item favorable memiliki nilai tertinggi pada pernyataan "Sangat Setuju" dan penilaian terendah pada pernyataan "Sangat Tidak Setuju". Skala attachment style terdiri atas 18 item. Skala ini mengukur empat dimensi, yaitu fearful-avoidant attachment style yang terdiri dari 5 item, preoccupied attachment style terdiri dai 4 item, dismissing attachment style terdiri dari 4 item dan secure attachment style terdiri dari 5 item.

\section{Skala religiusitas}

Skala religiusitas dengan modifikasi dari alat ukur oleh Stefan Huber dan Odilo W. Huber (2012) yaitu The Centrality of Religiosity Scale (CRS). Item dalam skala ini berbentuk favorable dan unfavorable. Alat ukur ini terdiri dari 33 item, 15 item adalah item yang telah diadaptasi dalam aspek bahasa, sementara peneliti menambahkan 18 item baru. Alat ukur ini mengukur lima dimensi dasar, yaitu intellectual terdiri dari 7 item, ideology terdiri dari 9 item, public practice terdiri dari 6 item, private practice terdiri dari 6 item, dan religious experience terdiri dari 5 item. 


\section{HASIL PENELITIAN}

Besaran Muatan Independent Variable terhadap Dependent Variable

\section{Analisis Regresi}

\section{Tabel 1}

Model Summary

\begin{tabular}{lcccc}
\hline Model & R & R Square & Adjusted R Square & Std. Error of the Estimate \\
\hline 1 & $.324^{\mathrm{a}}$ & .105 & .060 & 9.18173
\end{tabular}

a. Predictors: (Constant), Fearful-avoidant, Preoccupied, Dismissing, Secure, Intellectual, Ideology, Public, Private, Experience, Jenis Kelamin

Berdasarkan tabel di atas, diketahui nilai $R$-Square sebesar 0,105 atau 10,5\%. Artinya proporsi varians dari dating violence yang dijelaskan oleh seluruh independent variable sebesar 10,5\%, sedangkan 80,5\% dipengaruhi oleh variabel lain di luar penelitian ini.

\section{Anova keseluruhan IV terhadap DV}

Tabel 2

ANOVA $A^{b}$

\begin{tabular}{|c|c|c|c|c|c|c|}
\hline Model & & Sum of Squares & df & Mean Square & $\mathbf{F}$ & Sig. \\
\hline \multirow{3}{*}{1} & Reg. & 1955.740 & 10 & 195.574 & 2.320 & $.013 b$ \\
\hline & Res. & 16692.240 & 198 & 84.304 & & \\
\hline & Total & 18647.980 & 208 & & & \\
\hline
\end{tabular}

a. Dependent Variable: Dating Violence

b. Predictors: (Constant), Fearful-avoidant, Preoccupied, Dismissing, Secure, Intellectual, Ideology, Public, Private,

Experience, Jenis Kelamin

Berdasarkan tabel di atas, diketahui bahwa nilai $\mathrm{p}$ (sig) pada kolom paling kanan adalah sebesar 0,013 atau dengan nilai $\mathrm{p}<0,005$. Dengan demikian hipotesis yang menyatakan terdapat pengaruh yang signifikan dari seluruh independent variable terhadap dating violence diterima, Artinya, ada pengaruh yang signifikan dari intellectual, ideology, public practice, private practice, religious experience, fearful avoidant, preoccupied, dismissing, secure dan jenis kelamin terhadap dating violence. Berdasarkan tabel koefisen regresi, diketaui bahwa terdapat dua variabel yang signifikan memberikan pengaruh terhadap dating violence, yaitu fearful-avoidant attachment style dengan signifikansi 0,003 dan jenis kelamin dengan signifikansi 0,010 .

\section{Proporsi varian}

Berdasarkan nilai proporsi varians masing- masing variabel, terdapat dua variabel yang secara signifikan memberikan sumbangan, yaitu: 
1. Variabel fearful-avoidant memberikan sumbangan sebesar $5,4 \%$ terhadap varians dating violence. Sumbangan tersebut signifikan dengan $F$ Change $=$ 11,753 , df1 $=1$ dan df2= 207 dengan Sig. $F$ Change $=0,001$ (Sig. $F$ Change $<$ $0,05)$.

2. Variabel jenis kelamin memberikan sumbangan sebesar $3 \%$ terhadap varians dating violence. Sumbangan tersebut signifikan dengan $F$ Change $=6,681, \mathrm{df} 1=$ 1 dan df2= 198 dengan Sig. $F$ Change $=0,010$ (Sig. $F$ Change $<0,05$ ).

\section{KESIMPULAN DAN SARAN}

\section{Kesimpulan}

Berdasarkan hasil analisis penelitian, dapat diambil kesimpulan bahwa terdapat pengaruh yang signifikan secara bersama- sama antara variabel attachment style, religiusitas, dan jenis kelamin terhadap dating violence pada remaja. Hasil pengujian hipotesis berdasarkan masing- masing dimensi secara terpisah menunjukkan bahwa hanya dimensi fearful avoidant, dari variabel attachment style dan jenis kelamin yang berpengaruh secara signifikan terhadap dating violence pada remaja. Sementara delapan dimensi lainnya tidak memiliki pengaruh yang signifikan. Delapan dimensi tersebut adalah preoccupied, dismissing, dan secure pada variabel attachment style serta intellectual, ideology, public practice, private practice dan religious experience pada variabel religusitas.

\section{Diskusi}

Pada penelitian ini, dapat diketahui bentuk dating violence yang paling banyak dilakukan adalah relational abuse, kemudian verbal emotional, kekerasan fisik, threatening berhavior, dan terakhir adalah kekerasan seksual. Kemudian tujuan penelitian ini adalah untuk melihat pengaruh variabel attachment style, religiusitas dan jenis kelamin terhadap dating violence pada remaja. Hasil penelitian dan pengujian hipotesis menunjukkan bahwa ada pengaruh yang signifikan secara bersama-sama antara variabel attachment style, religiusitas dan jenis kelamin terhadap dating violence.

Kemudian peneliti melakukan analisis lebih lanjut untuk mengetahui dimensi mana saja dari variabel attachment style, religiusitas dan jenis kelamin yang memberikan pengaruh signifikan terhadap dating violence. Berdasarkan hasil analisis masing-masing dimensi variabel attachment style, ditemukan satu dimensi yang memberikan pengaruh signifikan secara positif terhadap dating violence. Dimensi tersebut adalah fearful-avoidant. Sedangkan tiga dimensi lainnya, yaitu preoccupied, dismissing dan secure, ketika dianalisis secara terpisah tidak memiliki pengaruh yang signifikan terhadap dating violence.

Dimensi fearful-avoidant memiliki pengaruh yang signifikan secara positif terhadap dating violence, artinya semakin tinggi skor fearful-avoidant seseorang maka semakin tinggi pula skor dating violence. Artinya remaja dengan tipe fearfulavoidant, yaitu seseorang yang ingin memiliki hubungan dekat dengan teman sebaya namun takut akan penolakan dan sering merasa khawatir apabila melakukan sesuatu sendirian, cenderung lebih sering melakukan dating violence ketika memiliki pacar. Hasil menunjukkan bahwa remaja yang melakukan dating violence adalah mereka yang memiliki kesulitan dalam bersosialisasi dan 
beradaptasi dengan teman sebaya. Remaja ini kesulitan dalam memenuhi tugas perkembangan terkait dengan menjalin persahabatan yang erat dengan teman sebaya. Ketika seseorang dengan fearful- avoidant memiliki pacar, mereka cenderung akan menjadi over protective dan takut kehilangan yang berlebihan. Sehingga ketika terjadi konflik dalam hubungan tersebut, orang dengan fearfulavoidant akan melakukan dating violence sebagai upaya memaksa dan mengancam pacar mereka agar tidak mengakhiri hubungan.

Hasil ini sejalan dengan penelitian Henderson, Bartholomew dan Dutton (1997) yang menemukan bahwa fearful-avoidant memiliki hubungan dengan terjadinya dating violence, terutama kekerasan fisik. Henderson et.al. (1997) menjelaskan jika seseorang dengan fearful avoidant yang tinggi maka ia akan memiliki keterikatan emosi dengan pacar yang rendah, sedikit melakukan dengan pacar, serta menghindari diskusi apabila memiliki masalah dengan pacar mereka. selain itu, hasil yang mendukung juga ditemukan dalam penelitian Trifiani dan Margaretha (2012). Dalam penelitian tersebut ditemukan bahwa remaja dengan karakteristik fearful-avoidant memiliki kecenderungan lebih tinggi untuk melakukan dating violence dibandingkan dengan model attachment lainnya.

Kemudian berdasarkan analisis variabel religiusitas, ditemukan bahwa masing-masing dimensi dalam variabel religiusitas, yang terdiri dari intellectual, ideology, public practice, private practice dan religious experience, tidak ditemukan pengaruh yang signifikan terhadap dating violence. Hasil ini sejalan dengan penelitian Higginbotham, Ketring, Hibbert, Wring dan Guarino (2007), yang menyatakan bahwa tidak adanya hubungan antara dimensi- dimensi dalam religiusitas dengan dating violence ketika dianalisis secara terpisah. Hasil yang serupa juga ditemukan dalam penelitian Koch dan Ramirez (2010) bahwa dimensi-dimensi dalam religiusitas, yaitu kepercayaan seseorang pada agama dan praktik ibadah seseorang dalam beragama, ketika dianalisis secara terpisah ternyata tidak menunjukkan adanya pengaruh yang signifikan terhadap dating violence.

Jika dilihat berdasarkan perkembangan religiusitas pada remaja, akan sangat besar pengaruh dari keluarga terhadap religiusitas remaja. Kualitas hubungan antara orang tua-anak sangat penting untuk berkembangnya religiusitas remaja. Remaja cenderung akan mengikuti apa yang diajarkan dan dicontohkan oleh orang tua mereka mengenai agama dan tata cara beribadah. Berbeda dengan dewasa awal, seseorang akan lebih kritis terhadap agama yang diajarkan kepada mereka. Pada dewasa awal, seseorang akan lebih mempertanyakan mengenai Tuhan (Santrock, 2008). Sehingga dalam penelitian ini terdapat ketidaksesuaian untuk mengukur religiusitas pada remaja. Pada remaja, akan lebih cocok apabila yang diukur adalah pengaruh dari pendidikan keagamaan yang dilakukan orang tua atau sekolah, bukan dari pemahaman remaja mengenai makna agama itu sendiri. Seperti dalam penelitian Ellison et.al (2001) yang mengukur religuisitas pada remaja hanya berasarkan seberapa sering remaja menghadiri acara-acara keagamaan di gereja. Pada penelitian ini, religiusitas yang diukur lebih sesuai untuk dewasa awal, dimana seseorang sudah memiliki pemahaman dan keyakinan yang lebih matang. Oleh sebab itu mengapa religiusitas dalam penelitian ini menjadi tidak signifikan. 
Sementara itu, variabel jenis kelamin ketika dianalisis secara terpisah dari variabel lainnya memiliki pengaruh yang signifikan terhadap dating violence. Hasil ini menunjukkan bahwa adanya perbedaan gender yang mempengaruhi seseorang melakukan dating violence. Tidak hanya laki-laki yang dapat menjadi pelaku dating violence, tetapi perempuan juga. Perbedaannya, laki-laki cenderung melakukan dating violence dalam bentuk kekerasan fisik, seperti memukul dan menendang, karena pada dasarnya laki-laki memang memiliki kekuatan fisik yang lebih besar. Sementara perempuan juga dapat melakukan dating violence dalam bentuk kekerasan verbal emosional, seperti memaki dan mempermalukan pacar didepan umum (Williams, Ghandour \& Kub, 2008).

Mengingat hanya sebesar 10,5\% pengaruh dari seluruh iv terhadap dating violence, peneliti memberikan saran bagi penelitian selanjutnya untuk mempertimbangkan variabel lainnya yang dapat memberikan pengaruh terhadap dating violence, seperti parental attachment style. Selain itu, saran yang dapat peneliti berikan kepada remaja, orang tua, pihak sekolah, dan konselor sekolah agar menyadari dampak dari dating violence dengan melakukan tindakan preventif maupun kuratif baik dengan membangun komunikasi yang baik, menyalurkan potensi anak dalam kegiatan-kegiatan positif, hingga mengadakan seminar maupun penyuluhan mengenai bahaya dating violence.

\section{Saran}

\section{Saran teoritis}

Saran teoritis yang peneliti berikan adalah sebagai berikut:

1. Penelitian ini menggunakan attachment style sebagai faktor internal, dan dimensi fearful-avoidant dari variabel attachment style hanya memberikan pengaruh hanya sebesar $5,4 \%$. Pengaruh yang diberikan oleh attachment style dalam penelitian ini termasuk kecil. Berdasarkan referensi jurnal terdahulu, attachment style yang memberikan pengaruh besar adalah parental attachment style sementara dalam penelitian ini menggunakan peer attachment style.

2. Selanjutnya, faktor eksternal dalam penelitian ini adalah religiusitas. Namun dalam penelitian ini, religiusitas tidak memberikan pengaruh yang signifikan. Hal ini disebabkan karena religiusitas pada remaja sangat dipengaruhi oleh keluarga dan sekolah, sementara yang diukur dalam penelitian ini lebih cenderung pada pemahaman dan keyakinan remaja mengenai agama. Sehingga terdapat ketidaksesuaian dalam mengukur religiusitas. Berdasarkan teori perkembangan moral pada remaja, lebih baik menggunakan pengaruh pendidikan agama untuk mengukur religiusitas pada remaja.

\section{Saran praktis}

Berdasarkan hasil penelitian ini, jumlah siswa yang melakukan dating violence cukup banyak. Hal ini tentu saja sangat mengkhawtirkan, karena apabila dating violence pada remaja tidak segera ditangani, akan berlanjut pada bentuk kekerasan lainnya, misalnya domestic violence, dan dampak-dampak jangka panjang lainna. Oleh karena itu, penting untuk menghentikan segala bentuk kekerasan yang terjadi. Penelitian ini diharapkan dapat menjadi salah satu data pendukung untuk dilakukannya berbagai kegiatan yang bersifat preventif maupun kuratif terkait 
denganmengatasi isu dating violence. Oleh karena itu, peneliti memberikan saran praktis bagi pihak-pihak tertentu, seperti orang tua, pihak sekolah dan konselor sekolah. Saran tersebut adalah sebagai berikut:

\section{Orang tua}

a. Berdasarkan data deskriptif dalam penelitian ini, ditemukan bahwa tingkat dating violence yang terjadi cukup tinggi. Sehingga pentingnya peran orang tua untuk mengetahui masalah yang dialami oleh anak agar anak tidak terbawa pada pergaulan yang kurang baik. Cara yang dapat dilakukan adalah dengan mengembangkan pola komunikasi yang terbuka dengan anak, juga dengan mengikutsertakan anak pada kegiatan yang bermanfaat seperti mengikuti kursus maupun lomba, sehingga anak dapat mengembangkan potensi yang dimiliki dengan maksimal dan tidak memiliki waktu untuk pacaran.

b. Kemudian, ditemukan bahwa tingkat intellectual, ideology, private practice, dan religious experience siswa tergolong tinggi. Adapun peran orang tua dalam mempertahankan agar tingkat religiusitas anak tetap tinggi adalah dengan mengajak anak untuk berdiskusi mengenai permasalahan agama, serta menerapkan nilai-nilai agama dalam kehidupan sehari-hari dan mengajak anak mengikuti acara keagamaan bersama.

c. Selain itu, berdasarkan data penelitian, diketahui bahwa tingkat remaja yang memiliki tipe fearful-avoidant attachment cukup tinggi. sehingga penting orang tua untuk mengetahui bagaimana pola hubungan yang terjalin antara anak dengan teman sebaya melalui curhat dan komunikasi yang terbuka.

2. Pihak sekolah

a. Berdasarkan data dalam penelitian, fenomena pacaran pada remaja sangat besar, sehingga penting bagi pihak sekolah untuk menyadari kemungkinan terjadinya dating violence pada siswa. Cara yang dapat dilakukan pihak sekolah untuk turut mengatasi isu dating violence adalah dengan memberikan kegiatan yang bersifat preventif melalui kegiatan bimbingan atau seminar mengenai dampak-dampak negatif dari pacaran kepada siswa,memberikan berbagai kegiatan untuk menyalurkan hobi dan keterampilan yang dimiliki siswa.

3. Konselor sekolah

a. Peran konselor sekolah dalam membantu menangani isu dating adalah dengan memasukkan tema dating violenceuntuk dibahas pada sesi pelajaran bimbingan konseling. Metode yang digunakan dapat melalui diskusi dan sharing. Dengan begitu, konselor sekolah dapat mengetahui dinamika dating violence yang terjadi dikalangan siswa.

\section{DAFTAR PUSTAKA}

Asmarani, Devi. 2015. Kekerasan dalam pacaran fenomena sunyi di Indonesia. Diakses Pada 29 November2015, dari http://magdalene.co/news-450kekerasan-dalam-pacaran-fenomena- sunyi-di-indonesia.html

Barokah, Sabar. 2016. Pacaran dan ta'aruf menuju pernikahan dalam pandangan hukum Islam. Skripsi. Fakultas Syari'ah IAIN Purwokerto 
Baron, Robert A. \& Donn Byrne. 2005. Psikologi sosial edisi kesepuluh. Diterjemahkan oleh Ratna Djuwita. Jakarta: Erlangga

Bartholomew, Kim \&Loenard M. Horowitz. 1991. Attachment styles among young adults: a test of a four- category model. Jurnal of Personality and Social Psychology,61(2), 226-244

Bartholomew, Kim. 1990. Avoidance of intimacy: an attachment perspective. Journal of Social and Personal Relationships, 7, 147-178

Bowlby, John. 1977. The making and breaking of affectional bonds. Psychiat, 130, 201210

Caldwell, Jennifer E., Suzanne C. Swan \& V. Diane Woodbrown. 2012. Gender differences in intimate partner violence outcomes. Psychology of Violence, 2(1), 42-57 Detik News. 2008. 1 dari 5 ABG putri alami kekerasan seksusual saat pacaran. Diakses pada pacaran. Diakses Pada 29 November 2015, dari http://news.detik.com/berita/920753/1-dari-5abg-putri-alami-kekerasan- seksual-saat-pacaran

Ellison, Christopher G. \& Kristin L. Anderson. 2001. Religious involvement and domestic violence among U.S. couples. Journal for the Scientific Study of Religion, 269-286

Grych, John H. \& Kristen M, Kinsfogel. 2010. Exploring the role of attachment syle in the relation between family aggression and abuse in adolescent dating relationship. Journal of Aggression, Maltreatment \& Trauma, 19, 624640

Hazan, Cindy \& Phillip Shaver. 1987. Romantic Love Conceptualized as an Attachment Process. Journal of Persoality and Social Psychlogi, 52(3), 511524

Henderson, A. J.Z. K. Bartholomew \& D. G. Dutton. 1997. He loves me; he loves me not: attachment and separation resolution of abused women. Journal of Family Violence, 12(2), 169-191

Higginbotham, Brian J., Scott A. Ketring, Jeff Hibbert, David W. Wright \& Anthony Guarino. 2007. Relationship religiosity, adult attachment style and courtship violence experienced by females. Journal Family Violence, $22,55-62$

Huber, Stefan \& Odilo W. Huber. 2012. The centrality of religiosity scale. Religions, 3, 710-724

Jackson, Susan M. 1999. Issues in the dating violence research: a review of the literature. Aggression and Violent Behavior, 4(2), 233-247

Kaltim Post, 2015. Usia 15 tahun berhubungan intim gaya pacaran remaja kelewat merdeka. Diakses Pada 30 November

2015, dari http://kaltim.prokal.co/read/news/241331-usia-15-tahun berhubungan- intim

Kinsfogel, Kristen M. \& John H. Grych. 2004. Interparental conflict and adolescent dating relationships: integrating cognitive, emotional, and peer influences. Journal of Family Psychology, 18(3), 505-515

Koch, Jerome R. \& Ignacio Luis Ramirez. 2010. Religiosity, christian fundamentalism, and intimate partner violence among U.S. college 
students. Thesis. Texas Tech University, Dept. of Sociology, Antrophology, and Social Work

Kompas. 2008. Satu dari lima remaja putrid alami kekerasan seksual. Diakses pada30November 2016, dari http://health.kompas.com/read/2008/ 04/09/1319458/Satu.dari.Lima.Rema ja.Putri.Alami.Kekerasan.Seksual

McVay, Kristie Dawn. 2012. Using attachment theory to understand intergenerational transmission of intimate partner violence and implications for use in treatment and policy reform. Electronic Thesis. University of Pittsburgh, Master of Public Health, B.A

Miga, Erin M., Amanda Hare, Joseph P. Allen \& Nell Manning. 2010. The relation of insecure attachment states of mind and romantic attachment sylestoadolescent aggression in romantic relationships. Attachment \& Human Development, 12(5), 463-481

Murray, Christine E. \& Kerrie N. Kardatzke. 2007. Dating violence among college students: key issues for college counselors. Journal of College

Counseling, 10, 79-89

Mynatt, Cliffor R. \& Elizabeth Rice Allgeier. 1990. Risk facotrs, self-attributions, and adjustment problems among victims of sexual coercion. Journal of Applied Social Psychology, 20(2), 130-153

Ningtyas, Ika. 2012. KPAI: pacaran pertama anak Indonesia umur 12 tahun. Diakses Pada 30 November 2015, dari https://gaya.tempo.co/read/news/201 2/06/06/174408718/kpaipacaran pertama-anak-indonesia-umur-12- tahun

Pye, Michael Edith Frank, Alef Theria Wasim\& Abdurrahman Ma'sud. 2004. Religious harmony. Berlin: Walter deGruyter

Silverman, Jay G., Anita Raj, Lorelei A. Mucci, Jeanne E. Hathaway. 2001. Dating violence against adolescent girls and associated sustance use, unhealthy, weight control, sexual risk behavior, pregnancy, and suicidality. American Medical Association, 286(5), 572-579

Santrock. 2008. Adolescence. McGraw-Hill, New York

Stark, Rodney, \& Glock, Charles Y. 1968. American piety: the nature of religious commitment. USA: University of California Press

Straus, Murray A. 2004. Prevalence of violence against dating partners by male and female university students worldwide. Violence Againts Women, 10(7), 790-811

Straus, Murray A., Sherry L. Hamby, Sue Boney-McCoy \& David B. Sugarman.1996. The revised conflict tactocs scales (CTS2): development and preliminary psychometric data. Journal of Family Issues, 17(3), 283-316

Symons, Patricia Y., Maureen W. Groër, Patricia Kepler-Youngblood \& Victoria Slater. 1994. Prevalence and predictors of adolescent dating violence.Journal of Child \& Adolescent Psychiatric Nursing, 7(3), 14-23

Trifiani, Nessia Ragil \& Margaretha. 2012. Pengaruh gaya kelekatan romantic dewasa (adult romantic attachment style) terhadap kecenderungan untuk melakukan kekerasan dalam pacaran. Jurnal Psikologi Kepribadian dan Sosial, 1(2). 74-83 
Wekerle, Christine \& David A. Wolfe. 1999. Datingviolence in mid-adolescence: theory, sigficance, and emerging prevention initiatives. clinical psychology review, 19(4), 435-456

Williams, Jessica Roberts, Reem M. Ghandour\& Joan E. Kub. 2008. Female perpetration of violence in heterosexual intimate relationships: adolescence through adulthood. Trauma Violence Abuse, 9 (4), 227-249.

Wolfe, David A., Katreena Scott, Deborah Reitzel-Jaffe, Christine Wekerle, Carolyn Grasley\& Anna-Lee Straatman. 2001. Development and validation of the conflict in adolescent dating relationships inventory. Psychological Assessment, 12(2), 277-293. 